\title{
Gathering opinion and initiating debate: the success of the Delphi Method in purely qualitative research
}

\author{
Brian Cape
}

\section{Author}

Brian Cape graduated from the University of Northumbria in 2002, receiving an MA with distinction in Information and Library Management. He had previously received a BA First Class Honours in English Literature from the University of Sheffield. Brian is currently employed as an Information Librarian for the London Borough of Sutton.

Email: briancape7@yahoo.co.uk

\section{Occasion}

This article is based upon a dissertation completed in 2002 for the MA in Information and Library Management at the University of Northumbria. The dissertation was awarded the Library and Information Research Group Postgraduate Highly Commended Certificate in 2003.

\begin{abstract}
Certain evaluation criteria have emerged frequently from the published literature on Holocaust film. This suggested that it might have been possible to establish a list of such criteria, to provide a framework for the evaluation of Holocaust films. A Delphi survey of United Kingdom Holocaust Studies experts was used to investigate this possibility. The survey elicited in-depth opinions from the experts, which the researcher analysed in order to conclude that evaluating the success of a Holocaust film is dependent upon the subjective interpretation of the individual viewer. This article concentrates upon the methodology used in this study, examining the suitability of the Delphi Method as a tool for rich qualitative research.
\end{abstract}

\section{Acknowledgements}

The author is grateful to Shona McTavish and Jackie Urwin at the University of Northumbria for their advice and assistance.

\section{Introduction}

The purpose of this research was to discover whether a set of criteria could be established with which to evaluate the success of Holocaust films. All of the previous research into Holocaust film that the researcher reviewed was based upon 'rich' and 'deep' (Bryman, 1999, p. 36) qualitative data. Critical readings of Holocaust films have taken the form of both descriptive and analytical narratives supported by 'the judgement of knowledgeable individuals' (Dalkey, 1972, p. 4), usually the opinions of filmmakers and film critics. The research project was designed to collect this qualitative data, opinions and judgements that could be analysed and compared.

This article focuses upon the primary research element of the dissertation- the suitability, successes and failures of the Delphi Method. This was a particularly 
significant choice of methodology, and may have been the first application of the Delphi Method in the fields of Holocaust Studies and Film Theory. The researcher could not find a similar research project in any of the published literature. Nor could he find a Delphi survey dealing solely with opinion without attempting to quantify the findings or make predictions about the future. By relying only upon qualitative data, the researcher tested the suggestion made by Goodman that Delphi 'lends itself best to studies that want to gather opinion and initiate debate' (1987, p. 732).

\section{Choice of methodology}

It was obvious from the literature review that Holocaust film is a controversial subject that continues to provoke debate. A research method was required that could generate and encourage the discussion of different opinions, 'in the attempt to ensure that all relevant issues' were 'identified and explored' (Goldschmidt, 1996, p. 126). This immediately ruled out a one-off questionnaire, which could elicit opinions but not encourage an exploration of these opinions. Constraints of time, cost and geography also ruled out a series of individual interviews or focus groups. The Delphi Method was chosen because it suited the requirements of the research; it provoked discussion while also fitting the practical constraints of a 15-week and 20,000 word long Masters dissertation.

\subsection{Defining the Delphi Method}

In their seminal work, The Delphi Method: Techniques and Applications, (Linstone and Turoff, 1975) Linstone and Turoff refused to posit an explicit definition of the Delphi Method for two major reasons. Firstly, they believed that a research technique should be continuously evolving and redefining itself as it is applied to different areas of research: 'when something has attained a point at which it is explicitly definable, then progress has stopped' (Linstone and Turoff, 1975, p. 3). Most importantly, they believed that 'in its design and use Delphi is more of an art than a science' (Linstone and Turoff, 1975, p. 3). They did not want to constrain the researcher by stating that Delphi should be used in one specific way, and only in certain areas of research. The researcher should be free to make the Delphi Method their own, to tailor the technique to suit their own requirements.

Nevertheless, a general description of the Delphi Method must be provided before the researcher can adapt the technique to his/her own research. Delphi is usually used 'for collecting and distilling knowledge from a group of experts' (Ziglio, 1996, p. 3). The researcher purposefully selects respondents with the knowledge and experience necessary to provide useful insights into the problem or issue under investigation. The experts are asked to answer a question or a series of questions. This is usually done anonymously; the experts are in contact with the researcher but not each other. The researcher analyses the views of the experts and returns them for further comment, again ensuring anonymity. This process is repeated over a set number of rounds, allowing the experts to alter or defend their views in the light of what other experts have said. A well-designed Delphi survey should produce 'explicit, reasoned, self-aware opinions, expressed in the light of the opinions of associate experts' (Dyer, 1979, p. 45). 


\section{The purposive selection of respondents}

Delphi involves the purposive selection of respondents, not standard social science sampling procedures. As Goldschmidt stated, the goal of purposive selection is to 'identify as many relevant viewpoints as possible, in the attempt to ensure that all relevant issues are identified and explored' (1996, p. 126). This purposive selection has a serious impact on the outcome of the survey. The criteria for selection therefore have to be made transparent to the reader. Fischer (1978, p. 69), Dyer (1979, p. 43), and Drodge (1983, p. 6) are among the critics who have made this point clear.

The respondents initially selected were all tutors of Higher Education courses in the United Kingdom that deal with representations of the Holocaust in literature and film. Ziglio defined expertise as 'knowledge and practical engagement with the issues under investigation' (1996, p. 14). For this research project Holocaust Studies tutors clearly fit this description. The only important constant variable was that the respondents all taught at a similar high level, therefore they could be considered as experts. The research did not intend to measure the impact that different variables have upon opinion, therefore no attention was paid to other variables such as age, sex, and nationality.

All 20 experts in representations of the Holocaust listed by the Centre for Jewish Studies (Centre for Jewish Studies, 2002) were contacted and 10 agreed to take part in the survey. One expert subsequently decided to recommend one of her post-graduate students to take part in the survey in place of herself, stating that he had a greater understanding of Holocaust film and would therefore be of more use to the research. Although this student did not meet the criterion of being a university tutor, he was allowed to participate in the research because an expert in Holocaust Studies recommended him. His contributions to the Delphi survey were intelligent and extremely valuable to the research.

Goldschmidt suggested that a $66 \%$ response rate is adequate (1996, p. 127) and Van Beek planned for a 75\% response rate for his Delphi survey (1996, p. 196), but only $50 \%$ of the experts contacted agreed to participate in this research project. This response rate was considered to be adequate since the Delphi survey took place in June and July, a time when university tutors have a number of other commitments. The research had to be conducted and written up within 15 weeks, and with the large amount of qualitative data that was collected a panel of 10 experts was a good size. Literature on the Delphi Method supported a panel size of 10 experts: 'with a homogenous group of experts good results can be obtained even with small panels of 10-15 individuals' (Ziglio, 1996, p. 14).

\section{Carrying out the survey}

Adler and Sainsbury suggested that a Delphi survey should consist of three or four rounds that evolve from a loose and unstructured question to a more precise and structured exploration of the important issues (1996, p. 187). The 15-week time limit, however, meant that the survey could only consist of two rounds. Respondents had to be given sufficient time to reply to each round, and the researcher required enough time to analyse the large amount of qualitative data collected. A well-designed two round survey can still produce good results, and minimises the 'Delphi fatigue' that was mentioned by Drodge (1983, p. 4), and Linstone and Turoff (1975, p. 10). 
Important issues could still be identified by the experts in the first round of the survey, and discussed in the second round after the provision of feedback.

\subsection{Preparing the respondents for the survey}

An essential part of conducting any research is explaining to the respondents the purpose of the research and the intended outcomes: 'If respondents do not understand the aim of the Delphi exercise, they may answer inappropriately or become frustrated and lose interest' (Ziglio, 1996, p. 9). When initial contact was made with the respondents the purpose and process of the research were explained clearly and concisely. The respondents knew the level of the research, exactly when the survey would take place, and how much time would be required if they participated.

There was a temptation for the researcher to assume that his respondents would naturally be happy to contribute to research in their field of expertise. Any researcher who thinks like this is taking a big risk, especially when his respondents are university tutors and have so many other demands on their time. Measures were therefore taken to motivate the respondents. The survey was described as an opportunity for them to discuss important issues with their peers. It was emphasised that the input of the other experts would help the respondents to further develop their opinions and provide collective insights that may not have resulted from an individual perspective. As Linstone stated, a Delphi survey should 'provide the atmosphere of a fruitful communication process among peers' (Linstone and Turoff, 1975, p. 583). A wellmanaged Delphi survey should be a 'highly motivating' (Ziglio, 1996, p. 21) task for the experts to be involved in, and this was the intention of the researcher.

\subsection{The "pilot survey"}

Most good research involves a pilot survey that can highlight any potential problems and allow the researcher to remedy them before the survey proper commences: 'Piloting is a vital step in the process of perfecting and you neglect it at your peril' (Allison, 1996, p. 114). Strictly speaking, this research project did not use a separate pilot survey. There were only a limited number of experts willing to participate in the survey, and to pilot the Delphi question on any of them would have eliminated them from the survey, reducing the panel of experts still further. The solution decided upon was to send the question out to the experts before the survey began and ask for their comments. The comments that the experts made were not circulated to the other respondents, but used to indicate to the researcher whether they understood what was required of them.

One respondent misunderstood the purpose of the survey, stating: 'I wonder if the methodology is suitable (it seems to suggest that the answer can be calculated by "adding up the votes").' This highlights one of the problems resulting from the lack of face-to-face contact in a Delphi survey. Delphi 'misses the vital nonverbal, nonliterate components of interpersonal communications entirely' (Linstone and Turoff, 1975, p. 494). Consequently, all communication must be clear and instructions to respondents well explained. This misunderstanding indicated that a little further explanation was required as to why the Delphi survey was being used. Delphi was intended to stimulate in-depth discussion, not to conduct a quick "straw poll" of opinion. 
The first round question was: 'What criteria do you think should be used to evaluate the success of filmic representations of the Holocaust?' One respondent was unsure of exactly what this meant, stating 'This seems an impossibly broad question.' This response was not unexpected, as the question was deliberately ambiguous, and the "pilot survey" was intended to discover exactly how much explanation would need to accompany the question. The other respondents understood the question and made positive comments. One of the respondents said that he had recently set his students a similar question therefore he was well prepared for the survey:

'I am just dashing off to a conference of Holocaust experts so I will probably tap their bigger brains though my students have just answered a similar question for me so their answers will have more originality.'

The majority of responses were positive, but further explanation did accompany the Delphi question when the survey proper commenced. The respondents were assured that the broad nature of the question was intentional, as it was intended to elicit a wide range of issues and opinions for discussion. They were also assured that the word "success" in the question could be interpreted in any way they desired. It was important that the question should encourage respondents to qualify what they thought success meant in the context of Holocaust film; whether it is commercial success, artistic success, success in recreating events realistically, and so on. The "pilot survey" had indicated that the ambiguity of the Delphi question would only require minimal explanation, and the responses saw the experts discussing different types of success before identifying criteria by which to judge its achievement.

\subsection{The success of the first round}

The first round of a Delphi survey has been termed the 'exploration phase' (Ziglio, 1996, p. 9), where respondents explore the question and add new material. The respondents certainly explored the question in some detail. Most of the responses filled one side of A4 paper, and three stretched to two sides of A4. All respondents gave examples of specific Holocaust films to illustrate their opinions, and four respondents also quoted other critics to support their arguments. This indicated that the Delphi question and the accompanying explanation had been successful in ensuring that experts responded appropriately.

Eight of the 10 respondents replied within the stated two-week period. One respondent replied after being sent a reminder email, but another failed to reply after two reminder emails had been sent. This was taken to be an indication that he had decided not to participate in the survey. The irony of this is that the respondent who did not reply was the one who had initially expressed the most enthusiasm about the survey. He was quoted in section 4.2 as stating that he had recently set his students a question similar to the research question. The impact of his withdrawal was slight, as the other respondents gave very detailed answers and provided the researcher with enough data to analyse.

As Bertin stated, the 'care and attention' with which the questionnaire is answered by the experts 'is a function of their degree of motivation, and the time taken in replying is to a large extent a consequence of this' (1996, p. 165). From the first round responses it can be concluded that the respondents were well motivated to take part in 
the survey; responses were detailed, the respondents had obviously understood the question, and their replies were prompt.

\subsection{Producing the feedback}

Although the "pilot survey" proved extremely useful, it was limited in that it could not test the feedback that would be provided to respondents as part of the second round of the Delphi survey. Research has shown that the way in which the results are fed back to the respondents can affect the final outcome of the survey (Linstone and Turoff, 1975, p. 270). Obviously the feedback could not be tested at the beginning because it was only produced after the first round of the survey had concluded. The feedback could have been piloted on one expert after the conclusion of the first round, but this would have delayed the start of the second round of the survey and eliminated one expert from the panel. These constraints meant that the feedback was not piloted, but a lot of time and effort was spent ensuring that the feedback would be effective.

The researcher decided not to provide feedback in the form of a single summary statement that combined the individual opinions. It was decided instead to identify the criteria that respondents had used to evaluate Holocaust films, and present the opinions of the respondents under sub-headings relating to each criterion. Producing the feedback was therefore the first stage in data analysis, as it required the responses to be categorised according to the criteria that emerged.

Each respondent was identified by a letter, which meant that the other experts could respond to specific opinions. It was thought that this approach would be more successful in encouraging detailed discussion than total anonymity. Producing the feedback in this way counteracted the major problem with the iterative structure of the Delphi Method- the inevitable delay between the respondent's replies and the researcher's feedback. This lack of continuity can prevent the kind of in-depth conversation required to explore complex issues in detail. Producing a wellstructured feedback document promoted the 'depth of communication' (Ziglio, 1996, p. 20) required to yield new insights into the subject.

Identifying each participant by a letter produced more focused contributions and encouraged the experts to explain the reasons why they agreed or disagreed with specific opinions:

'knowing all the arguments a person has made for or against a given position allows people better to tailor their own arguments in response, and also allows the expression of more complex individual viewpoints' (Turoff and Hiltz, 1996, p. 62).

Combining responses into a summary statement would not have indicated how many other experts had the same opinion, and it would have masked subtle differences in the experts' thinking, making it appear that their opinions were exactly the same when the thinking underlying the opinion was different. An example from the feedback document will help to illustrate how this was avoided:

'Respondents A, C and D all considered it important that a Holocaust film carries significance for a contemporary audience: 'How well a film manages to bridge the gap between then and now, how relevant its 
portrayal of past lives is for the present of the viewer, is essential.' (Respondent D) Respondent C stated that it is also important 'to universalise the Holocaust and relate it to comparable world events."

This feedback statement begins by indicating that only respondents A, C and D mentioned the criterion of contemporary significance. Respondent A commented very briefly on this criterion, therefore no quotation from this respondent has been included. Respondents $\mathrm{C}$ and $\mathrm{D}$, however, discussed the issue in more detail and expressed slightly different opinions. A single summary statement could easily have overlooked this subtle difference. Including a quotation from each of these respondents did the opposite, highlighting the slight difference in their thinking and allowing the other respondents to address each quotation separately.

To give the respondents as full an understanding as possible of the reasoning behind each expert's opinion would have required completely unmediated feedback.

Obviously, due to the volume of qualitative data received by the researcher, this was not an option. The feedback had to present the relevant opinions in a coherent manner, revealing as much of the thinking behind them as possible in a short document. The researcher ensured that the feedback document was no longer than 1500 words.

There was a temptation for the researcher to draw his own conclusions from what the experts had said and include these in the feedback. This was avoided, as it would have introduced serious researcher bias into the feedback and had an impact upon the opinions expressed in the second round of the survey. Obviously the researcher selected what to include in the feedback document, but his own interpretation was added after the survey had concluded.

\subsection{The second round of the survey}

The second round of the survey gave respondents the opportunity to re-evaluate their original answers 'in the light of comprehensive feedback on the responses of the whole group' (Ziglio, 1996, p. 9). This was the 'evaluation phase' (Ziglio, 1996, p. 9) of the survey, when the experts assessed each other's opinions and came to their conclusions. The success of the feedback in stimulating discussion was indicated by the second round responses. The respondents specifically addressed the opinions presented in the feedback document, developing these opinions further and producing insights that would not have resulted from a single questionnaire or a series of single interviews. They referred to the other respondents by the letters that had been used. Respondent $\mathrm{C}$ provided the best example of the success of the feedback. He laid out his second round response exactly as the feedback document had been laid out, commenting on the opinions that had been expressed under each of the separate subheadings. This confirmed the way in which the iterative structure of the Delphi Method can produce an informed collective opinion.

The major problem with the second round of the survey was the lower response rate. As Jillson stated: 'There is usually a decrease in response rates for the second round of a Delphi study, particularly those involving voluntary participation' (Linstone and Turoff, 1975, p. 132). Of the nine experts still involved in the survey, six responded to the second round within the stated two week time period. A reminder was sent to the other three, and one expert replied shortly after this. She said that she had already 
replied, but since the researcher had not received this reply it can only be assumed that it was sent to the wrong email address. The respondent was, however, eager to compose another reply, which was received by the researcher two days later. This respondent clearly believed the survey to be worthwhile, or she would not have taken the time to produce a second reply after the initial reply was lost.

Another of the respondents replied to the reminder by stating that, for personal reasons, she had not been able to find the time to reply to the second round of the survey. She did eventually respond, but her response was received too late to be included in the data analysis. Only one respondent did not reply to either of the reminders sent out, and it is impossible to say why he decided not to participate in the survey any further.

The decrease in the response rate for the second round of the survey did have an impact upon the data analysis. For the seven respondents that replied, the second round of the survey was when they reached their conclusions and expressed the opinions that had been informed by the feedback document. These were the most interesting opinions that were expressed, because they were formed by considering the opinions of the other experts involved in the survey. The lower response rate meant that there was less evidence to support some of the conclusions that were reached. The respondents that replied to the second round of the survey were quoted more often in the data analysis, as the second round responses were more detailed and more focused than the first round responses. The detail of the second round responses gave sufficient data to analyse, but it was disappointing that some respondents did not comment on the opinions of their peers. Overall, the decision to have an initial panel of 10 respondents was supported. Despite the panel being reduced to seven, a large amount of qualitative data was collected and conclusions could still be drawn from this data.

\subsection{How the data was analysed}

A clear and systematic approach to data analysis was essential, as the analysis had to begin as soon as the responses to the first round of the Delphi survey had been received. In order to prepare the feedback the responses were categorised according to the criteria that the experts had identified. This was carried out in the most simple but effective way possible. Responses were colour-coded to refer to the different experts, photocopied numerous times, cut out, and glued onto separate sheets. Each sheet contained all the comments made on a particular criterion. Areas of agreement and disagreement were highlighted, and interrelationships between the categories were indicated. 'Reducing' (Creswell, 1994, p. 154) the data in this way made it easier to identify specific criteria and to organise the comments that the respondents had made on each criterion.

Data from the first round of the Delphi survey was the most time-consuming to analyse. The data was largely unstructured and many of the comments could be placed in a number of the categories that emerged. As a result of the feedback between rounds, the second round of the survey produced more structured data. The respondents had specifically addressed the comments made in the feedback document therefore categorisation was much easier. After the second round responses, however, the categories were revised to fit the new data. It was important throughout the data analysis that the categories were always derived from the data, rather than attempting 
to force the data into pre-existing categories (Maykut and Morehouse, 1994, p. 127). Bryman emphasised the 'emergent' design of qualitative research $(1999$, p. 36). For this reason the criteria identified from the literature review provided a guide, but the survey data was initially treated separately from this secondary research.

During the second round of the Delphi a number of comments were made that related to genre, a category that the literature review had identified but that had not emerged from the first round data. Consequently, this category was set up after the second round of the Delphi survey. Some criteria from the literature review did not emerge at all from the Delphi survey data. This was a valid outcome, as the Delphi survey was intended to discover the criteria that the panel of experts considered important. They were not expected to mention every criterion that had been identified from the literature.

Categorising the data, breaking them apart and 'imposing order on them' (Moore, 2000, p. 146), was the first stage in data analysis. Although 'no order will fit the data perfectly' (Moore, 2000, p. 145), it is easier to get a sense of the whole when it can be broken into the sum of its parts. This was particularly important in research that was attempting to identify individual criteria, requiring the data to be broken down into these separate criteria where possible. The next stage was putting the data back together and interpreting them to form 'a larger, consolidated picture' (Creswell, 1994, p. 154). The aim was 'to achieve a synthesis that brings the segments together in new and original ways to throw light on the issues and to advance our understanding' (Moore, 2000, p. 146). This was done through comparison. A matrix was drawn that presented the full contributions of each respondent vertically, and each of the individual criteria horizontally. All of the primary data was contained on one large sheet of paper, making it easy to compare opinions and to follow each respondent's line of thinking by reading their full responses.

An important part of the analysis of qualitative data is putting the data into context in order to give it meaning (Moore, 2000, p. 136). This was done in the data analysis by referring back to the literature review wherever appropriate, so that the responses from the Delphi survey could be interpreted in the context of previous research into Holocaust film. The intention was to 'triangulate' the data (Creswell, 1994, p. 158) to discover where the Delphi survey responses agreed with the opinions of the filmmakers and critics in the literature review, and also where they disagreed. This comparison improved the 'internal validity' of the survey and 'strengthens reliability' (Creswell, 1994, p. 167-8). Where similar opinions emerged from the primary and the secondary data, 'the credibility of the interpretation' was 'enhanced' (Ertmer, 1997, p. 169). With 'interpretative-descriptive' (Maykut and Morehouse, 1994, p. 123) research it is important that the researcher's interpretation is always supported by a description of what has been discovered. This was achieved in a descriptive narrative that analysed the data and presented the researcher's interpretation of this data.

\section{$5 \quad$ Conclusions}

Conducting the Delphi survey was a rewarding and largely successful experience. In practice, the Delphi Method did prove to be well suited to gathering the 'rich' and 'deep' (Bryman, 1999, p. 36) qualitative data required within the time available. The respondents expressed their opinions in considerable detail, and even in a short two 
round survey sufficient data was collected. Delphi was an excellent research method to use for 'gathering opinions' (Fischer, 1978, p. 64) and initiating debate. The iterative nature of the Delphi Method provided a structure within which important issues were identified and then discussed.

\subsection{The success of the Delphi survey}

This discussion was provoked, of course, by the Delphi question: 'What criteria do you think should be used to evaluate the success of filmic representations of the Holocaust?' Linstone and Turoff suggested that one reason for failure in a Delphi survey is 'overspecifying the structure of the Delphi and not allowing for the contribution of other perspectives related to the problem' $(1975$, p. 6). This was avoided by leaving an element of ambiguity in the Delphi question, therefore allowing the respondents to introduce any perspectives that they felt were relevant to the "success" of a Holocaust film. This was integral to the success of the survey. In both rounds the respondents discussed the ways in which "success" could be defined in relation to Holocaust films. This proved to be the most important discussion that took place, as the subjective nature of evaluating "success" was fundamental to the conclusions that were eventually reached.

Two rounds were enough for the experts to reach a consensus on the importance of the subjective evaluation of Holocaust films. There were some unresolved disagreements over the importance of some of the criteria that were identified, but this was definitely not an inadequacy of the research method. In fact, these disagreements supported the conclusions about the subjective nature of evaluation and the impossibility of establishing a set of criteria with which to judge the success of Holocaust films.

The researcher had considered quantifying the Delphi survey data as a way of determining the relative importance to the respondents of the various criteria that were identified. This would have involved a third round to the survey in which the respondents were asked to rank, on a scale of one to five, how important they felt each criterion was. It is common in a Delphi survey to ask respondents to rank items in this way, enabling quantitative analysis to be carried out on the data (Ziglio, 1996, p. 10). In hindsight, the decision not to increase the length of the survey for this purpose seemed correct. Areas of agreement and disagreement in relation to the criteria that were identified could be easily pinpointed without quantification. In addition, the respondents accepted that the importance of each criterion depended upon the subjective judgement of the individual viewer. Given this conclusion, quantification would have proved unnecessary and probably frustrating to the respondents.

A number of the respondents made positive comments on the success of the Delphi survey. They appeared to have enjoyed the opportunity to develop their opinions in a structured discussion with other experts. One respondent commented: 'Thank you for sharing your synthesis of the various responses to the first phase of your survey. It seems a very valuable exercise.' This pointed to the success of the feedback document, which invited the respondents to comment on the opinions that the other experts had expressed. This was the area in which the respondents felt they had gained most from the survey. One respondent stated 'the agreements and divergences of opinion are very interesting,' and another commented 'the feedback has certainly 
been useful.' The positive comments made by the respondents assured the researcher that they considered the survey worthwhile.

\subsection{Possible improvements to the survey}

The main improvement considered was how to remedy the low response rate. The length of the survey seemed appropriate, and the feedback document was the subject of a number of positive comments. It is likely, therefore, that the time at which the survey was conducted was the major reason for the low response rates. University tutors are very busy during the months of June and July, and a number of the respondents that were initially contacted stated that they were unfortunately too busy to participate in the survey. If the survey had been carried out at the beginning of term rather than after term had finished, perhaps more than 10 experts would have agreed to participate.

Another improvement would have been to introduce member checking. Given the enthusiastic responses to the feedback document, discussed above in section 5.1, the respondents would probably have enjoyed the opportunity to read and comment upon the data analysis. Member checking would have ensured that the respondents agreed with the way in which the researcher had represented and interpreted their comments. This would definitely have strengthened the reliability of the conclusions. It would also have further combated the danger of ambiguity. As Delphi does not involve face-to-face contact there is always the possibility that ambiguous statements can be wrongly interpreted. This was addressed by asking the respondents to avoid ambiguity in their answers, but member checking would have taken this one step further. The respondents would have felt more involved in the research if they had been asked to comment on the outcomes, and the researcher would have been certain that his analysis was acceptable to them.

\subsection{Further research}

Subjectivity was an important and unavoidable element of this research. The primary and secondary data that were collected were all personal opinions, that is, the opinions of Holocaust Studies experts and the opinions of filmmakers and critics. The researcher used his knowledge of Holocaust film to interpret the responses and to express his own opinion on the issues that were discussed. The 'unique interpretation' (Creswell, 1994, p. 159) that emerged was that of the researcher, but it was based upon opinions expressed by others knowledgeable in the field of Holocaust film. One of the findings of the survey was that evaluating the success of a Holocaust film is dependent upon the subjective judgement of the individual carrying out the evaluation. This supported the necessarily subjective nature of this research project.

To prove that this conclusion is generally applicable would require extensive research using a more heterogeneous group of respondents. If the researcher were to further investigate the subjective evaluation of Holocaust films then he would definitely select respondents with more widely varying knowledge of films and of the Holocaust. If the intention were to improve the 'generalisability' (Maykut and Morehouse, 1994, p. 56) of the conclusions then a method of random sampling could be used. This would enable a comparison between the ways in which viewers with different degrees of knowledge and experience evaluate Holocaust films. The conclusions that were reached in the dissertation were the researcher's 'unique 
interpretation of events' (Creswell, 1994, p. 159), based upon data that was collected from a purposefully selected group of respondents.

\section{References}

Adler, M. and Sainsbury, R. (1996) Alternative approaches to the computerisation of Social Security: reflections on a Delphi exercise. In: Adler, M. and Ziglio, E. (eds.) Gazing into the Oracle: the Delphi Method and its application to social policy and public health, Jessica Kingsley Publishers.

Allison, B. et al. (1996) Research Skills for Students, Kogan Page.

Bertin, G. (1996) Delphi Techniques and the planning of Social Services: the prevention of dependency among the old. In: Adler, M. and Ziglio, E. (eds.) Gazing into the Oracle: the Delphi Method and its application to social policy and public health, Jessica Kingsley Publishers.

Bryman, A. (1999) The debate about quantitative and qualitative research. In: Bryman, A. and Burgess, R. (eds.) Qualitative Research: volume 1, Sage Publications.

Centre for Jewish Studies, Holocaust Studies in the UK.

URL: http://www.mucjs.org/hsstats.htm [accessed 06/07/02]

Creswell, J. (1994) Research design: qualitative and quantitative approaches, Sage Publications.

Dalkey, N. (1972) Studies in the quality of life: Delphi and decision-making, Lexington Books.

Drodge, S. (1983) Delphi Technique: some practical considerations, Library and Information Research News, 6(21), 4-6.

Dyer, E. (1979) The Delphi Technique in library research, Library Research 1(1), 1979, 41-52.

Ertmer, P. (1997) Common qualitative research designs. In: Leedy, P. (ed.) Practical research: planning and design, Prentice-Hall.

Fischer, R. (1978) The Delphi Method: a description, review, and criticism, The Journal of Academic Librarianship 4(2), 64-70.

Goldschmidt, P. (1996) A comprehensive study of the ethical, legal and social implications of advances in biochemical and behavioural research and technology. In: Adler, M. and Ziglio, E. (eds.) Gazing into the Oracle: the Delphi Method and its application to social policy and public health, Jessica Kingsley Publishers.

Goodman, C. (1987) Delphi technique: a critique, Journal of Advanced Nursing 12(6), 729-34.

Linstone, H. and Turoff, M. eds. (1975) The Delphi Method: techniques and applications, Addison-Wesley Publishing Company. 
Maykut, P. and Morehouse, R. (1994) Beginning qualitative research: a philosophic and practical guide, The Falmer Press.

Moore, N. (2000) How to do research: the complete guide to designing and managing research projects, Library Association Publishing.

Turoff, M. and Hiltz, S. (1996) Computer-based Delphi processes. In: Adler, M. and Ziglio, E. (eds.) Gazing into the oracle: the Delphi Method and its application to social policy and public health, Jessica Kingsley Publishers.

Van Beeck, E. (1996) The use of the Delphi Method in forecasting accidents in the year 2000. In: Adler, M. and Ziglio, E. (eds.) Gazing into the oracle: the Delphi Method and its application to social policy and public health, Jessica Kingsley Publishers.

Ziglio, E. (1996) The Delphi Method and its contribution to decision-making. In: Adler, M. and Ziglio, E. (eds.) Gazing into the oracle: the Delphi Method and its application to social policy and public health, Jessica Kingsley Publishers.

\section{WORD COUNT: 6384}

